\title{
Grabados imperceptibles. Pisadas y paralelas del sitio Piedra Auque, Departamento Minas, noroeste de la Provincia de Neuquén
}

(4ernando E. Vargas* y Adán Hajduk**

\section{Resumen}

En este trabajo se presenta un nuevo sitio con grabados rupestres localizado en el valle del arroyo Auque, en el noroeste de la provincia de Neuquén. Se trata de grabados efectuados sobre un afloramiento de pirofilita, roca similar a la esteatita o comúnmente denominada piedra sapo o jabón. Debido a la notable excepcionalidad de su uso como soporte efectuamos una caracterización del mismo, como también de los motivos presentes, las técnicas empleadas, su localización espacial y visibilidad arqueológica. De este modo, discutimos la particularidad de los diseños grabados dentro del contexto de producción rupestre de la cuenca del río Neuquén y el norte Neuquino en general.

Imperceptible engravings. Footprints and parallels of the site Piedra Auque, Minas Department, northwest of the Province of Neuquén

\begin{abstract}
This paper presents a new site with rock engravings located in the valley of the Auque stream, in the Northwest of the Neuquén province. These are engravings made on an outcrop of pyrophyllite, a rock similar to soapstone or commonly called stone toad or soap. Due to the remarkable exceptionality of its use as a support, we carry out a characterization of it, as well as the motives present, the techniques used, its spatial location and archaeological visibility. In this way, we discuss the particularity of the designs recorded within the rock production context of the Neuquén river basin and the North of Neuquén in general.
\end{abstract}

Recibido:

15 de marzo de 2018

Aceptado:

1 de septiembre de 2018

\section{Palabras clave}

Roca pirofilita

Grabados

Pisadas

Paralelas

Norte neuquino

\section{Keywords}

Pyrophyllite rock Engravings Foot prints Paralels North of Neuquén

* Instituto de Investigaciones en Diversidad Cultural y Procesos de Cambio (IIDYPCA), Universidad Nacional de Río Negro (UNRN) - CONICET. Av. de Los Pioneros 2350 (CP R840oAHN) San Carlos de Bariloche, Río Negro, Argentina. E-mail: femmanuelvargas@gmail.com

** Museo de la Patagonia "Dr. F. P. Moreno", Centro Cívico s/n (CP R840oAHN) San Carlos de Bariloche, Río Negro, Argentina. E-mail: ahtrapalanda@gmail.com 


\section{Introducción}

El objetivo de este trabajo es presentar el sitio que denominamos Piedra Auque, ubicado en el noroeste de la provincia de Neuquén, emplazado en un importante afloramiento de roca pirofilita, que actualmente pertenece al predio de una cantera que explota este mineral con fines comerciales. El hallazgo se produjo en el marco de la revisita a los sitios con grabados de la cuenca alta del río Neuquén relevados por Fernández ([1979] 2000) en la década de 1970, con el objetivo de evaluar comparativamente los diferentes contextos de producción y circulación de códigos visuales en el norte neuquino en función de diferentes estrategias de ocupación y uso del espacio (Vargas, 2015a).

Una de las características más destacables del sitio es el tipo de roca soporte seleccionada para la confección de los grabados, así como también el tipo de motivos que allí se encuentran. De este modo, en el presente trabajo caracterizamos el tipo de soporte, los motivos grabados y las técnicas empleadas para la elaboración de los mismos, así como también la localización de los paneles y la accesibilidad al sitio. En el relevamiento de los grabados se consideraron algunas variables cualitativas observables en los paneles que nos permitieron identificar diferentes técnicas de grabado y pátinas con el fin de inferir posibles momentos de ejecución de los grabados. Con estos datos, discutimos y remarcamos su excepcionalidad de forma comparativa con el resto de los sitios con grabados del norte neuquino, al ser una producción visual de muy baja visibilidad.

\section{Ubicación geográfica y marco ambiental}

El sitio Piedra Auque se encuentra a unos $8 \mathrm{~km}$ al noreste de la localidad de Varvarco, sobre un afloramiento de roca pirofilítica, a la altura del tramo medio del arroyo Auque, tributario del río Varvarco (Figura 1). En cuanto al ambiente, el sitio se halla a una altura de $1.761 \mathrm{~m}$ s.n.m. sobre el faldeo oeste de la Cordillera del Viento, en un típico ambiente de estepa patagónica (Cabrera, 1976). Específicamente, los paneles con grabados se emplazan sobre la barranca de la margen izquierda del arroyo Auque, a unos $15 \mathrm{~m}$ de altura por encima del lecho. Esta barranca, suponemos, se formó por la acción de la erosión ocasionada por el arroyo, el cual segmentó en dos el mencionado afloramiento.

La roca pirofilita pertenece a la Formación Arroyo El Auque, de edad estimada Devónica, que aflora únicamente en este tramo del arroyo en un área de $1 \mathrm{~km}^{2}$ (Zappettini y Dalponte, 2009). Las rocas de esta formación están compuestas por esquistos pirofilíticos que contienen principalmente pirofilita, aunque en algunos casos se encuentra asociada a cianita, diáspora y cuarzo en muy poca proporción (Zappettini y Dalponte, 2009). La pirofilita que nos interesa aquí es un filosilicato de alúmina hidratado cuya fórmula es $\mathrm{Al}_{2}\left(\mathrm{Si}_{4} \mathrm{O}_{10}\right)(\mathrm{OH})_{2}$ (Asensio, Blanquer y Ramón, 2011). Entre sus cualidades se destaca por ser una roca de brillo céreo, con coloraciones que van del blanquecino a amarillento o verdosos y de grisáceos a negros. Por su parte, dependiendo de sus componentes minerales asociados, su rango de transparencia va de traslúcida a opaca. Finalmente, la pirofilita es una roca que posee muy baja dureza - de 1 a 1,5 en la escala de Mohs- y esta característica la convierte en una roca muy friable que al rayarla deja un polvo blanco similar al talco.

\section{Antecedentes}

Una de las características principales de los sitios del norte neuquino,es el tipo de soporte utilizado para la confección de los petroglifos. Así, tanto para el caso de los sitios de la cuenca del río Neuquén (Cuneo, 2017; Fernández, [1979] 2000; Vega et al., 1996) como los sitios de la cuenca del río Curi-Leuvú (Hajduk y Cuneo, 2009; Vargas, 


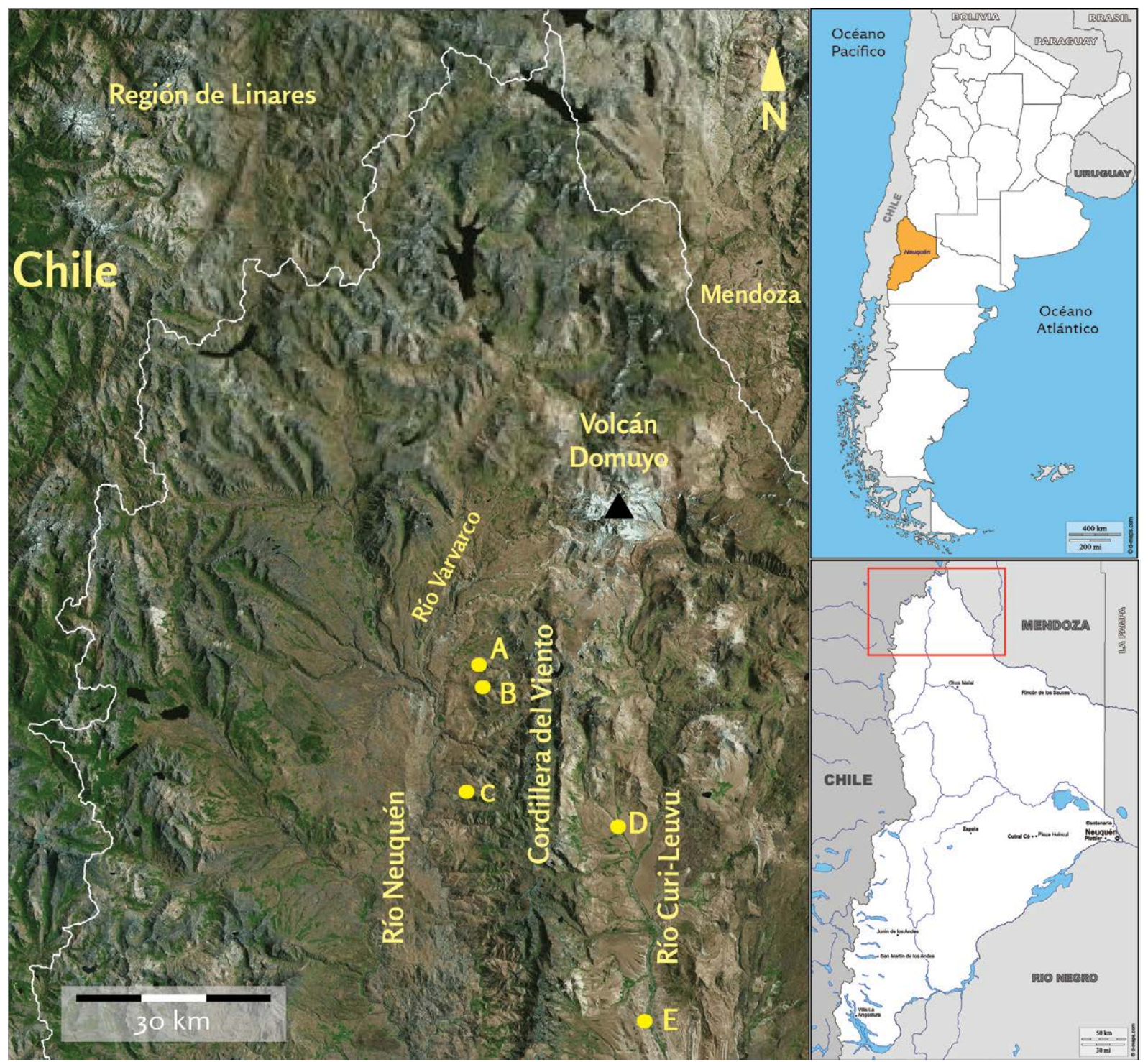

Figura 1. Sitios mencionados en el texto. A) sitio Piedra Auque; B) sitio El Chacay; C) sitio Colo-michi-có; D) localidad Molulco-Mogotillo; E) sitio Caepe Malal I.

2015b), casi la totalidad de los petroglifos han sido efectuados sobre roca andesita ${ }^{1}$. Esta roca tiene su origen en la Formación Cordillera del Viento (Guerello, 2006) y se halla distribuida a ambos lados de la Cordillera homónima. Litológicamente, esta formación está compuesta por plutonitas y volcanitas en proporciones similares, siendo las volcanitas más abundantes que los basaltos, andesitas, dacitas y riolitas (Guerello, 2006).

Específicamente para la cuenca neuquina, Fernández ([1979] 2000) observa que en su totalidad los grabados fueron realizados con la técnica de picado mediante percusión sobre los distintos soportes, siendo el ancho relativamente uniforme entre 1 y $2 \mathrm{~cm}$. En cuanto a la profundidad de los surcos, también es poco variable siendo en promedio unos $2 \mathrm{~mm}$, a excepción de dos sitios emblemáticos como Colo-michi-có y El Chacay, donde los surcos suelen ser más profundos aunque en estos casos también la pátina posee una textura más rugosa (Fernandez, [1979] 2000). En el caso de la cuenca del río Curi-Leuvú, los grabados de la localidad Molulco-Mogotillos además de poseer
1. A excepción de los sitios Las Chaquiras y El Chacay que, según Fernández ([1979] 2000), se utilizó basalto para la confección de los grabados. 
2. El caso del sitio de Colo-michicó, posee motivos figurativos que remiten a pisadas humanas (Fernández, [1979] 2000). similitudes con los tipos de motivos de la cuenca neuquina (Hajduk y Cuneo, 2009; Vargas, 2015b), poseen similitudes respecto de la técnica empleada. También en este caso los grabados se efectuaron con la técnica de picado mediante percusión, donde el producto visual final son grabados con bajo relieve de un ancho uniforme de entre 1 y $2 \mathrm{~cm}$ y una profundidad de entre 1 y $2 \mathrm{~mm}$ (Vargas, 2015b).

Otra de las particularidades del arte rupestre grabado del norte neuquino es su repertorio de motivos, que han sido rotulados como pertenecientes al estilo paralelas (Fernández, [1979] 2000; Menghin, 1957). Así, en términos generales, casi la totalidad de los sitios enmarcados dentro del estilo de paralelas se caracterizan por contener escasos motivos figurativos, tales como pisadas o rastros de animales, manos humanas y antropormorfos ${ }^{2}$ (Fernández, [1979] 2000). No obstante, una excepción en este contexto lo representa el sitio Buraleo (Cuneo, 2017), el cual estaría más vinculado con el repertorio de motivos del estilo guayquivilo (Niemeyer y Weissner, 1972-1973) debido a que posee una importante cantidad de rastros de pisadas y algunas improntas de mano y pie humanas (Cuneo, 2017). Por su parte, en la cuenca del río Curi-Leuvú se ha constatado comparativamente mayor presencia de motivos figurativos, tales como pisadas animales - principalmente tridígitos- junto a ocasionales antropomorfos y zoomorfos (Hajduk y Cuneo, 2009; Vargas, 2015b).

En suma, el norte neuquino posee una marcada homogeneidad en cuanto al tipo de producción de grabados rupestres tanto desde la dimensión visual de los diseños como de las técnicas empleadas y, fundamentalmente, los soportes seleccionados. Estas similitudes a ambos lados de la Cordillera del Viento han sido interpretadas como la evidencia de posibles redes de circulación, interacción social y complementariedad entre diferentes grupos (Hajduk y Cuneo, 2009). Incluso desde una perspectiva macro regional, este contexto visual norneuquino ha permitido formular y contrastar algunas hipótesis referidas a la dinámica de circulación de información (Romero y Re, 2014) y códigos visuales (Vargas, 2015b), en función de algunos interrogantes y expectativas arqueológicas a diferentes escalas espaciales (Barberena, 2013; Barberena et al., 2017).

\section{Materiales y métodos}

Con respecto al análisis rupestre, trabajamos en tres niveles: soporte, paneles y motivos. A nivel de soporte registramos su conformación topográfica, accesibilidad y características cualitativas de la roca (dureza, color, textura). A nivel de los paneles se registró la orientación cardinal de cada uno y sus dimensiones de ancho y largo. En cuanto a los motivos, se tomó como parámetro la definición de motivo de Gradin (1978), a la vez que se usó como referencia el repertorio de motivos de Fernández ([1979] 2000) y el criterio clasificatorio entre motivos figurativos y no figurativos propuesto por Fiore (2011).

En cuanto al análisis de las técnicas, se retomaron las referencias y parámetros de Álvarez y Fiore (1995) para la identificación de técnicas de grabado en función de las huellas de los surcos y los artefactos involucrados. En este sentido, las autoras postulan que las técnicas de picado, raspado, machacado y horadado dejan huellas en forma de U mientras que la técnica de inciso deja huellas en $\mathrm{V}$. Teniendo en cuenta los antecedentes mencionados sobre las técnicas empleadas en la manufactura de los grabados del norte neuquino, los autores no explicitan si las técnicas que se emplearon efectivamente fueron por picado o machacado ya que, según Álvarez y Fiore (1995), la primera precisaría de un percutor y un cincel con filo, mientras que la segunda solo de un percutor con filo. Para el presente trabajo, ante la imposibilidad de poder diferenciar la presencia de una u otra técnica en función de los artefactos involucrados, utilizamos el término picado como sinónimo de machacado. Así, el registro de los trazos se realizó 


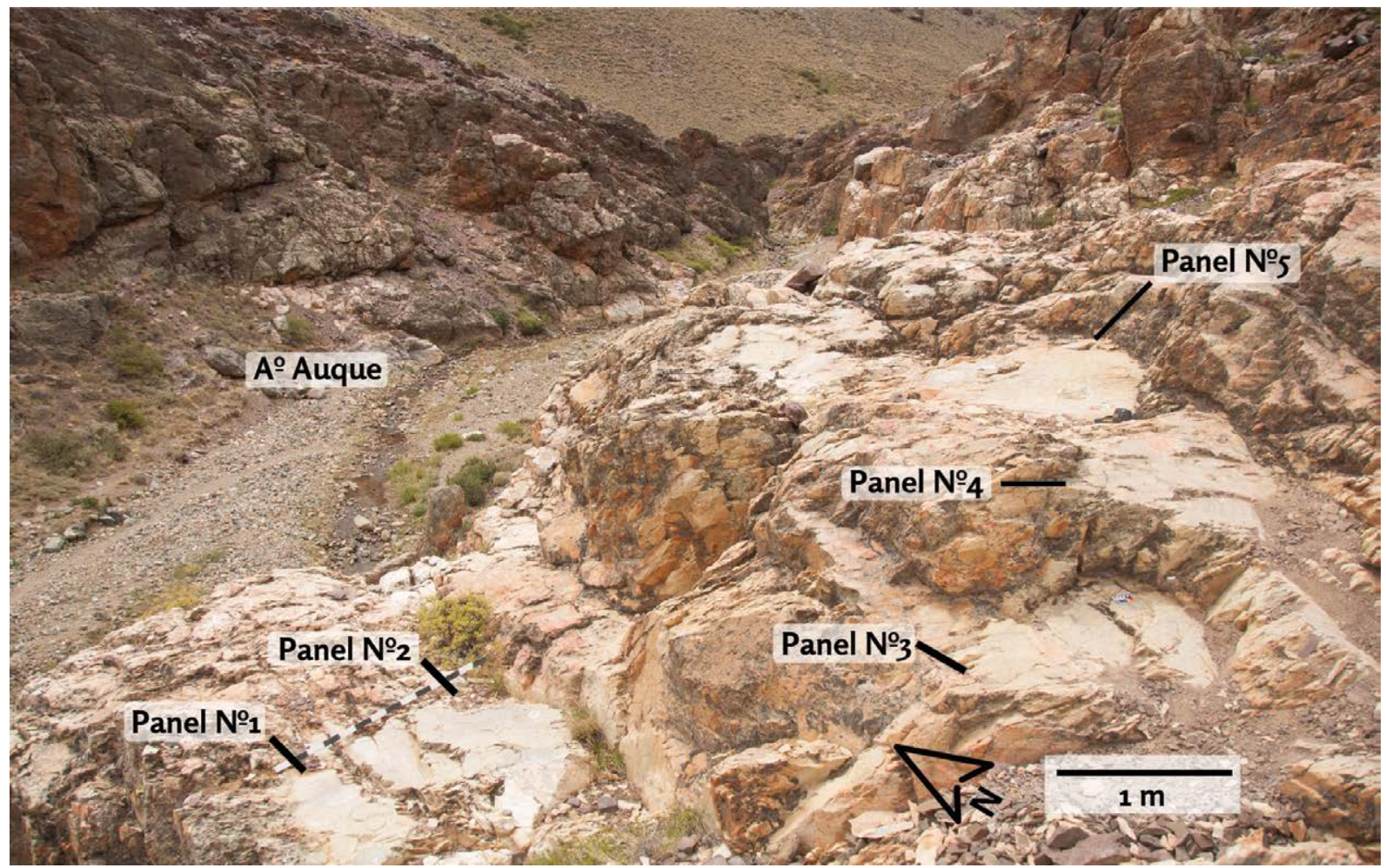

Figura 2. Ubicación de los paneles sobre la barranca. Al fondo, el arroyo Auque.

en función del tratamiento de la técnica de picado. De este modo, diferenciamos el picado continuo, cuando se conforman trazos homogéneos (lineales o de cuerpo lleno) y picado discontinuo cuando se conforman trazos lineales compuestos por sucesión de puntos de percusión separados.

El relevamiento de los grabados se realizó mediante diferentes secuencias de fotos de proximidad y dibujos a mano alzada. Esta información nos permitió diferenciar con mayor resolución en gabinete posibles incisiones modernas tales como marcas de ganado o bien marcas producto del pisoteo de animales de pastoreo, como las cabras entre otros. Con estos datos establecimos, de forma cualitativa, una gradación de pátinas que van desde las más blanquecinas (actuales) hasta las más oscuras, de tono marrón similar a la pátina del soporte (antiguas). Para esta gradación se tomó como referencia un grabado moderno hallado en las inmediaciones y también las incisiones efectuadas por los autores sobre muestras de roca para obtener el valor de dureza en la escala de Mohs.

\section{Resultados}

Tal como mencionamos, la ubicación de sitio se halla sobre el borde o flanco alto de la barranca sur del afloramiento de roca pirofilita. De este modo, el acceso al sitio resulta difícil debido a que el relieve es abrupto e irregular en ese sector del morro. Así, para acceder a los paneles grabados es necesario trepar, tanto si se ingresa desde el cauce del arroyo como si se ingresa descendiendo por el sector superior desde el faldeo oeste de la Cordillera del Viento. Incluso, luego de sortear el primer acceso, aproximarse a los paneles también resulta difícil ya que es necesario sortear sectores del afloramiento que se encuentran seccionados en planos horizontales formando una suerte de escalera irregular sobre el borde de la barranca. 


\section{Paneles}

En cuanto a los paneles grabados, se pudo identificar un total de cinco de ellos, los que se localizan en al menos tres niveles de pequeñas terrazas o escalones subhorizontales, distribuidas según un eje noroeste-sureste (Figura 2). Todos los paneles relevados conforman planos horizontales, con una leve inclinación en algunos sectores hacia el oeste. Según esta disposición, en la primera terraza se encuentran los paneles $\mathrm{n}^{\circ} 1$ $\mathrm{y} \mathrm{n}^{\circ} 2$, con un tamaño promedio de unos $25 \mathrm{~cm}$ de ancho por unos $80 \mathrm{~cm}$ de largo y unos $80 \mathrm{~cm}$ de ancho por unos 1,40 $\mathrm{m}$ de largo, respectivamente. Por su parte, en la segunda terraza, se ubica el panel no 3 que mide unos $55 \mathrm{~cm}$ de ancho por unos $35 \mathrm{~cm}$ de largo, siendo el más pequeño de todos. Finalmente los paneles $\mathrm{n}^{\circ} 4$ y n ${ }^{\circ} 5$ se ubican en la terraza más alta, siendo sus medidas $1,10 \mathrm{~cm}$ de ancho por unos $65 \mathrm{~cm}$ de largo y $1,10 \mathrm{~m}$ por un 1,50 de largo respectivamente.

\section{Motivos y técnicas}

Se identificaron un total de 28 motivos pertenecientes a ocho tipos de motivos distribuidos en los cinco paneles (Tabla 1). En esta ocasión no se incorporaron motivos de factura actual o modernos identificados en otros sectores del afloramiento. Así, en el panel no 1 (Figura 3) se destaca el motivo en forma de "ocho" que, a diferencia del resto de los motivos presentes, fue producido mediante una técnica de picado continuo que dio lugar a un surco profundo de entre $1,4 \mathrm{~cm}$ y $1,2 \mathrm{~cm}$ de profundidad y un ancho que varía entre $5 \mathrm{~cm}$ de ancho máximo a $1,4 \mathrm{~cm}$ de ancho mínimo. Un segundo motivo, ubicado muy próximo al anterior, representa un círculo realizado por picado continuo y el resto del trazo por picado discontinuo. Ambos motivos presentan pátina de tonalidad semejante a la superficie natural no grabada. En el panel no 2 (Figura 3) se identificó un total de tres motivos: un círculo realizado mediante picado continuo y dos tridígitos producidos mediante picado discontinuo. Estos tridígitos se observan algo más claros y blanquecinos, producto de un repicado moderno que no alcanza a borrar la pátina más oscura de los picados antiguos.

El panel no 3 presenta la mayor cantidad de motivos de tridígitos con un total de ocho (Figura 3). En proximidad de uno de ellos se aprecia un motivo compuesto de una serie de puntos agrupados - unos 25 en total- muy sutiles, elaborados por picado de no más de $1 \mathrm{~cm}$ de diámetro cada uno. La mayoría de ellos presenta restos de posibles líquenes de tonalidad grisácea en su interior, favoreciendo su percepción. Finalmente, este panel presenta un motivo de línea quebrada aislado. Respecto de los motivos tridígitos, salvo uno, todos ellos fueron realizados por picado continuo, aunque en grado tal de que no conformaron un surco en bajo relieve pero sí un cambio de textura perceptible al tacto que se contrasta levemente con la superficie naturalmente lisa del panel. El restante tridígito se ejecutó por unos pocos picados discontinuos. En suma, estas características técnicas sumadas a la pátina relativamente homogénea de los motivos, dificulta notablemente su visualización tornándolos casi imperceptibles.

En referencia al panel no 4 , al igual que en los paneles precedentes, aquí también los motivos grabados se ejecutaron por picado (Figura 4). Entre los motivos presentes se identificaron un total de seis, uno en forma de segmento ondulado irregular y dos tridígitos alineados con trazos de no más de $1 \mathrm{~cm}$ y una profundidad de 1 $\mathrm{mm}$. Estos últimos fueron realizados por picados continuos que no dejan relictos de la superficie natural previa al grabado. En cuanto al motivo en forma ondulada e irregular, está constituido por unos 20 círculos pequeños unidos entre sí por segmentos. Particularmente, el diámetro de estos círculos no superan los $2 \mathrm{~cm}$ de ancho y los segmentos que los unen son trazos muy finos de $2 \mathrm{~mm}$ de ancho y una profundidad de no más de $1 \mathrm{~mm}$. Una de las características de este motivo es que sus trazos fueron producidos mediante picado discontinuo de forma tal que no llega a conformarse un trazo homogéneo. A continuación de los motivos mencionados se halla un motivo 


\begin{tabular}{|c|c|c|c|c|c|c|c|}
\hline Tipo de Motivo & Panel 1 & Panel 2 & Panel 3 & Panel 4 & Panel 5 & Total $f$ & Total \% \\
\hline Figura en "8" & 1 & - & - & - & - & 1 & 3,57 \\
\hline Círculo simple & 1 & 1 & - & - & 2 & 4 & 14,29 \\
\hline Círculo de cuerpo lleno & - & - & - & - & 1 & 1 & 3,57 \\
\hline Tridígitos & - & 2 & 8 & 2 & - & 12 & 42,86 \\
\hline Serie de puntos agrupados & - & - & 1 & 1 & 1 & 3 & 10,71 \\
\hline Línea quebrada & - & - & 1 & - & - & 1 & 3,57 \\
\hline $\begin{array}{l}\text { Figura de círculos de cuerpo lleno } \\
\text { unidos por segmentos }\end{array}$ & - & - & - & 1 & - & 1 & 3,57 \\
\hline Línea ondulada irregular & - & - & - & 1 & - & 1 & 3,57 \\
\hline $\begin{array}{l}\text { Círculos unidos con apéndice lineal } \\
\text { ondulante }\end{array}$ & - & - & - & 1 & - & 1 & 3,57 \\
\hline Antropomorfo & - & - & - & - & 1 & 1 & 3,57 \\
\hline Líneas ondulantes paralelas múltiples & - & - & - & - & 2 & 2 & 7,14 \\
\hline Total & 2 & 3 & 10 & 6 & 7 & 28 & 100,00 \\
\hline
\end{tabular}

Tabla 1. Frecuencias y porcentajes de tipos de motivos por panel.

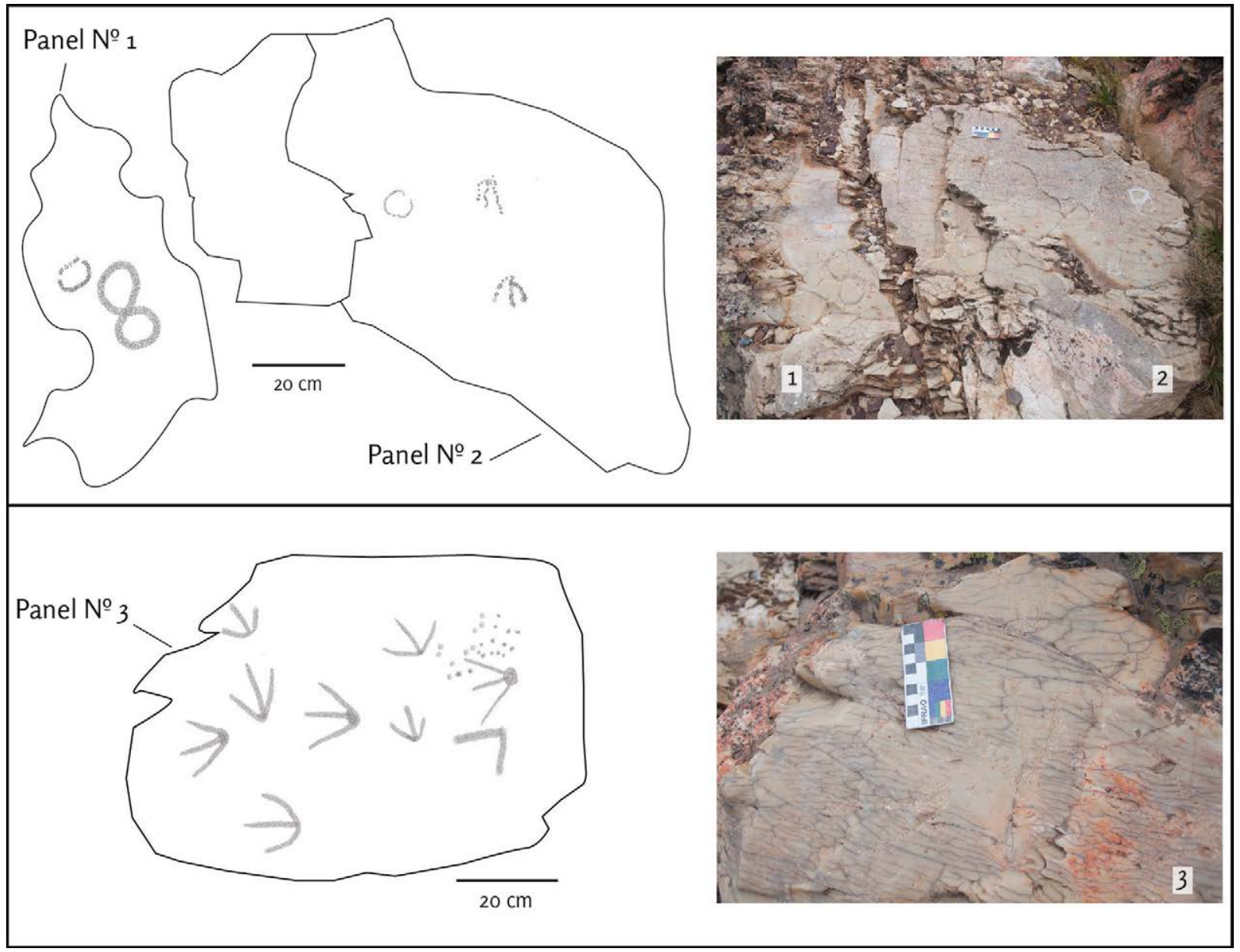

Figura 3. Paneles 1, 2 y 3 con sus respectivos motivos. 
3. Estas diferencias de tonalidad se representan en el panel $n^{\circ} 5$ con tonos de grises (Figura 4). compuesto por una serie de seis círculos unidos que conforman una especie de $\mathrm{C}$, con los dos extremos que se prolongan en forma de apéndice lineal ondulante. Finalmente un sector del panel presenta una serie discreta de puntos agrupados.

En el panel $n^{\circ} 5$ (Figura 4) cabe destacar que, a diferencia de los anteriores paneles, se observaron, además de grabados por picado, aquellos ejecutados por incisión con instrumento de filo extremo agudo que dio lugar a surcos de perfil en $\mathrm{V}$ de diversa profundidad. De esta manera, si bien todos los grabados presentan pátina similar a la natural de la roca, poseen características que las diferencian. Así, las pátinas observadas en las depresiones producto del picado en este panel se ven de tonalidad rosada, en tanto que en los trazos por incisión se aproximan a las pátinas claras de las superficies naturales del panel. Los trazos por incisión lineal resultan más visibles que los realizados por picado debido a la continuidad del trazo y su nitidez y la sombra regular que se suele observar al interior del grabado 3 .

En referencia específica a los motivos del panel $n^{\circ} 5$, se destaca uno de considerable tamaño que se interpreta como la figura esquemática de un antropomorfo (Figura 4). Según una observación detallada, consideramos que fue realizado, en primera instancia, por picado conformando un tronco rectilíneo con representación de miembros anteriores y posteriores donde el cuello y cabeza se observan, en proporción, poco destacados. En un momento posterior, al eje del tronco se le sobregrabó una línea por incisión de considerable profundidad proyectándose, la misma, algo más allá del encuentro del tronco con los miembros inferiores. Acaso no se descarta que pueda estar representando el falo del antropomorfo. Por debajo de esta figura antropomorfa se observaron dos círculos, uno realizado por picado discontinuo y otro por picado continuo dando lugar, en este caso, a un surco homogéneo y relativamente ancho en leve bajo relieve.

Finalmente, entre los motivos ejecutados mediante picado de la superficie rocosa, el panel presenta una serie de líneas paralelas múltiples de considerable extensión (Figura 4). En un sector, éstas se superponen con parte de los miembros superiores e inferiores de un lado del antropomorfo. La similitud de pátina observada en el sector de superposición de ambos motivos no permite plantear una diferencia en la secuencia temporal de sus respectivas ejecuciones. Por último, considerando los grabados por incisos lineales, sean estos más cortos o más largos, su ejecución se estima posterior a los grabados por picado, sin poder inferir la distancia temporal precisa que pueda mediar entre ellos.

\section{Discusión}

En primer lugar queremos resaltar la excepcionalidad del sitio dentro del contexto de producción visual del norte neuquino debido no solo al tipo de diseños que allí se encuentran y el tipo de soporte elegido sino también por el producto visual final generado. En este sentido, si bien la baja dureza de la roca habría facilitado la labor en la ejecución de grabados, las superficies naturales que fueron seleccionadas, al ser de tonalidades claras, brindan un bajo contraste figura-fondo otorgando así el carácter casi imperceptible a los diseños. No obstante, tal como hemos observado con las incisiones modernas o actuales, es probable que al momento mismo de la ejecución de los grabados y por un lapso de tiempo relativamente corto, los motivos hayan sido visibles dado que las superficies afectadas inmediatamente se tornan de color blanquecino producto del polvillo fino generado al triturar la roca. Sin embargo, la escasa profundidad de los surcos grabados en conjunción con la elevada friabilidad y rápida volatilidad del polvillo fino posterior a la ejecución nos indica que los ejecutantes no buscaron un efecto visual de alto contraste entre la figura y el fondo. De esta manera, asumiendo que 


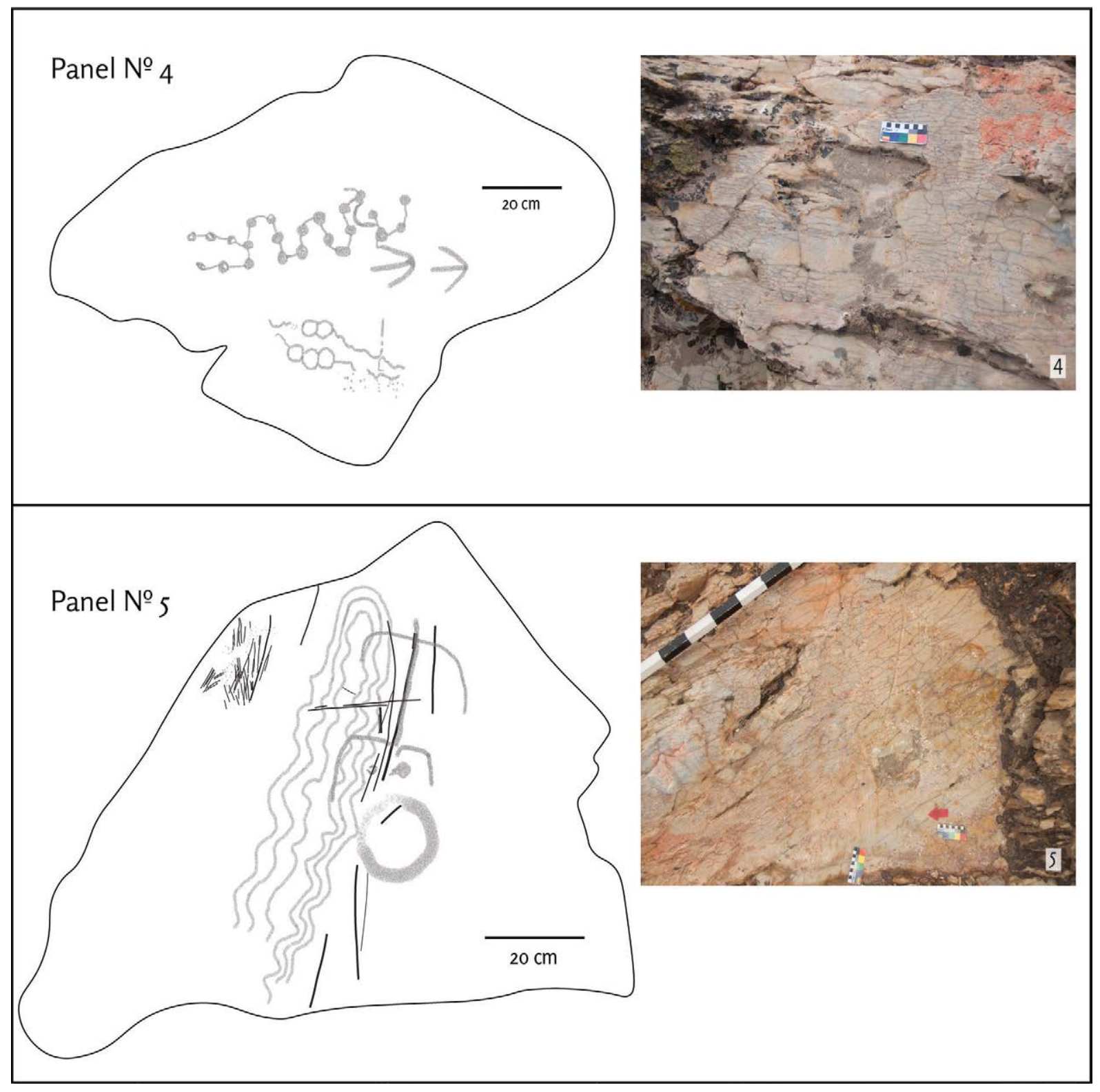

Figura 4. Paneles 4 y 5 con sus respectivos motivos.

los grabadores poseían el conocimiento del comportamiento y las propiedades físicas de la roca, consideramos que las características visuales de los grabados sumado al difícil acceso al emplazamiento y la orientación de los paneles en posición casi horizontal, contribuyen integralmente a otorgar una muy baja visibilidad al sitio, aspecto que consideramos habría sido intencional.

Esta situación, como adelantamos, no se corrobora para los otros contextos rupestres del norte neuquino, donde las características visuales de los diseños junto a la elección de bloques erráticos andesíticos y/o planchones como soportes y su distribución en el espacio (Vargas, 2015b) configuran un contexto rupestre significativamente diferente. En este sentido, la elección intencional de las rocas andesitas que poseen pátinas con tonalidades marrones oscuras, con texturas y durezas sensiblemente diferentes a la pirofilita, tiene como consecuencia la obtención de un producto y efecto visual final con mayor visibilidad, configurando una relación figura-fondo con el panel bien definida. 
4. Según estos autores, la cronología de ambos estilos se extendería desde el siglo XII al siglo XVI de nuestra era, con lo cual sugerimos que el sitio Piedra Auque tiene una cronología similar. Sin embargo, la cronología propuesta por los autores citados aún hoy día no cuenta con fechados absolutos o contextos arqueológicos que permitan establecer cronologías relativas más ajustadas. En este sentido, la asignación cronológica de los grabados del norte neuquino, y en particular del sitio Piedra Auque, dista de ser un tema concluido.
Considerando ahora el repertorio de motivos presentes en los cinco paneles descriptos, se destaca la presencia de los motivos figurativos y fundamentalmente la recurrencia de los tridígitos. Particularmente, estos motivos representan el $42 \%$ del total del sitio (Tabla 1) y se encuentran concentrados principalmente en el panel $n^{\circ} 2$. A su vez, solamente dos tridígitos se encuentran asociados a un motivo que posee algunas similitudes con el grupo de los "alfileres" descripto por Fernández ([1979] 2000) como perteneciente al repertorio del estilo de paralelas. En relación a esto último, otro de los motivos que tendría vinculación morfológica con aquellos motivos asignables al estilo de paralelas es la serie de líneas ondulantes paralelas descriptas para el panel $n^{\circ} 5$. En este sentido, si bien los grabados analizados se podrían vincular con el repertorio de motivos del estilo de paralelas (Fernández, [1979] 2000), efectivamente el sitio Piedra Auque tendría mayor vinculación con el repertorio de motivos presentes en los sitios rotulados bajo el denominado estilo guayquivilo, que poseen un elevado porcentaje de motivos de rastros de animales (Niemeyer y Weissner, 1972-1973, p. 454) ${ }^{4}$. En este sentido, tal como mencionamos arriba, si bien el ámbito de la cuenca alta del río Neuquén se destaca por la escasa representación motivos figurativos en general, la presencia de motivos figurativos tales como los tridígitos y un antropomorfo esquemático en el sitio Piedra Auque constituye a priori junto con el sitio Buraleo (Cuneo, 2017) un contexto visual diferente respecto del contexto general de producción rupestre de la cuenca alta del río Neuquén.

En suma, consideramos que estas diferencias respecto de las condiciones de visibilidad, variabilidad de técnicas y repertorio de motivos, abonan la hipótesis de una circulación diferencial de información y códigos visuales inherentes a estos contextos, mediada por prácticas de producción rupestre con fines visuales y comunicativos diferentes (Vargas, 2015a).

\section{Consideraciones finales}

Los grabados del sitio Piedra Auque constituyen sin duda una novedad dentro del contexto rupestre del norte neuquino debido a sus particulares características visuales. Así, este sitio brinda la oportunidad de continuar debatiendo la presencia y configuración de los clásicos estilos definidos para el norte neuquino así como también para la región del Talca y Linares con los cuales, sin duda, guardan estrechas vinculaciones. En este sentido, debemos afrontar con nuevas herramientas teórico-metodológicas cómo interpretar la variabilidad de motivos, soportes y contextos de visibilidad arqueológica rupestre, debido a que posiblemente refieran a contextos de producción y circulación de códigos visuales diferentes.

Finalmente, el sitio Piedra Auque resulta destacable para comenzar a indagar en sus múltiples y posibles usos por parte de los grupos humanos en el pasado. Como hemos constatado, el sitio se emplaza en un afloramiento único en su tipo dentro de la cuenca alta del río Neuquén y posiblemente de todo el norte neuquino, con lo cual estimamos que por sus particulares cualidades de roca fácil de tallar, textura, colores y brillo de su superficie, la pirofilita habría representado una materia prima potencialmente atractiva, tanto para la producción de arte rupestre como para la posible fabricación de artefactos. En este sentido, resta efectuar prospecciones intensivas en el área que abarca el afloramiento de roca pirofilita con el fin de identificar nuevos grabados rupestres así como también evidencias materiales que den cuenta de otros posibles usos y/o aprovechamientos de este tipo de roca.

\section{Agradecimientos}

A los vecinos de Varvarco, fundamentalmente a Isabel Jorquera quien nos informó sobre la existencia de grabados en la cantera de Piedra Auque. A los representantes de 
la empresa Auquen. S.A. por facilitarnos el ingreso a la cantera y al sitio. Finalmente a Claudia Della Negra por su constante apoyo y a los evaluadores de la revista por sus valiosos aportes. 


\section{Referencias citadas}

» Álvarez, M. y Fiore, D. (1995). Recreando imágenes: Diseño de experimentación acerca de las técnicas y los artefactos para realizar grabados de arte rupestre. Cuadernos del Instituto Nacional de Antropología y Pensamiento Latinoamericano, 16, 215-239.

"Asensio, S. I., Blanquer, J. M. G., y Ramón, H. M. (2011). Filosilicatos 2: 1, https://riunet. upv.es/handle/10251/12885. (Acceso: 10 de marzo, 2018).

" Barberena, R. (2013). Biogeografía, competencia y demarcación simbólica del espacio: modelo arqueológico para el norte de Neuquén. Intersecciones en Antropología, 14, 367381.

» Barberena, R., Romero Villanueva, G., Lucero, G., Fernández, M. V., Rughini, A. A, y Sosa, P. (2017). Espacios internodales en Patagonia septentrional: biogeografía, información y mecanismos sociales de interacción. Estudios Atacameños, 56, 57-75.

"Cabrera, A. (1976). Regiones fitogeográficas argentinas. Enciclopedia Argentina de Agricultura y Jardinería (2da. Edición, Tomo 2). Buenos Aires: ACME S.A.C.I.

"Cuneo, E. M. (2017). Sitio Buraleo: representaciones rupestres del "estilo Guaiquivilo" en el noroeste neuquino, departamento Minas, República Argentina. En F. Gordon, R. Barberena y V. Bernal (Eds.), El poblamiento humano del norte de Neuquén. Estado actual del conocimiento y perspectivas (pp.75-99). Buenos Aires: Aspha.

» Fernández, J. ([1979] 2000). Las piedras con marcas de la cordillera del Viento. Arte rupestre en el departamento Minas, Neuquén, Argentina. Buenos Aires: Sociedad Argentina de Antropología.

"Fiore, D. (2011). Materialidad visual yarqueología de la imagen. Perspectivas conceptuales y propuestas metodológicas desde el sur de Sudamérica. Boletín del Museo Chileno de Arte Precolombino, 16(2), 101-119.

" Gradin, C. (1978). Algunos aspectos del análisis de las manifestaciones rupestres. Revista del Museo Provincial, I, 120-137.

"Guerello, R. (2006). Geología del sector norte de la fosa de Chos Malal. Provincia de Neuquén. (Tesis de Licenciatura inédita), Universidad de Buenos Aires, Argentina.

" Hajduk, A. y Cúneo, E. M. (2009). Representaciones rupestres en la Cuenca del río Curi Leuvú (departamento Chos Malal, Provincia del Neuquén, República Argentina). Informe preliminar. En M. Salemme, F. Santiago, M. Alvarez, E. Piana, M. Vázquez y E. Mansur (Eds.), Arqueología de la Patagonia. Una mirada desde el último confín (pp. 515526). Ushuaia: Utopías.

»Menghin, O. (1957). Estilos de arte rupestre de la Patagonia. Acta Praehistórica, I, 57-87.

» Niemeyer, F. y Weisner, L. (1972-1973). Los petroglifos de la Cordillera Andina de Linares (provincias de Talca y Linares, Chile). Actas del Sexto Congreso de Arqueología Chilena (Volumen II, pp. 405-470). Santiago de Chile: Universidad de Chile.

"Romero, G. y Re, A. (2014). Representaciones rupestres del noreste de Neuquén (Patagonia Septentrional). Primeras tendencias espaciales y temporales. Comechingonia, 18, 73-92.

»Vargas, F. E. (2015a). Espacios, imágenes y comunicación visual rupestre a través del tiempo, Dpto. Chos Malal, Neuquén. Presentación al CONICET. Manuscrito Inédito. 
"Vargas, F. E. (2015b). Petroglifos del Norte Neuquino en la cuenca del Curi-Leuvú. Un abordaje desde la Arqueología del Paisaje. (Tesis de Licenciatura inédita), Universidad Nacional de Rosario, Argentina.

»Vega, T., Martínez, M., Piombo, M., Bestard, P., Gelós, M., y Seró, C. (1996). Profundización de los aspectos estéticos de petroglifos y pictografías de la provincia del Neuquén. I parte. Chungara. Revista de Antropología Chilena, 28(1/2), 365-379.

»Zappettini, E. O. y Dalponte, M. (2009). Hallazgo de hierro bandeado en el basamento del sector noroccidental de la Cordillera del Viento, provincia del Neuquén: aspectos estratigráficos y metalogenéticos. Revista de la Asociación Geológica Argentina, 64(3), 550-554. 